\title{
A cegueira histérica de Adolf Hitler: histórico de um boletim médico*
}

\section{The hysterical blindness of Adolf Hitler: record of a medical chart}

\section{GERHARD KÖPF ${ }^{1}$}

\begin{abstract}
Resumo
Em 1918, no hospital militar de Pasewalk, o psiquiatra professor Edmund Forster trata, por meio da hipnose, o cabo Adolf Hitler de uma "neurose de guerra" (cegueira histérica). Em 1933, Hitler assume o poder sobre a Alemanha nazista. Pouco tempo depois, Forster entra em contato com um grupo de escritores que viviam em exílio em Paris e passa sigilosamente a eles os seus conhecimentos sobre o caso. O escritor Ernst Weiss, também médico, usa essas informações de Forster para escrever o seu romance A Testemunha Ocular (Der Augenzeuge), que é publicado somente em 1963. O professor Forster comete suicídio em 1933, depois de sofrer uma campanha de denúncias difamantes. Weiss também se suicida em 1940, quando as tropas alemãs invadem Paris. Várias outras pessoas relacionadas ao boletim médico sobre Hitler são assassinadas pela Gestapo.
\end{abstract}

Palavras-chave: Hitler, cegueira histérica, história da psiquiatria, literatura, neurose de guerra.

\begin{abstract}
In 1918, in a military reserve hospital located in the small Pomeranian town of Pasewalk, the neuropsychiatrist Prof. Edmund Forster treated Adolf Hitler, an Austrian caporal suffering from a war neurosis (hysterical blindness), using suggestive techniques. Soon after the Hitler's ascension to the power in the Nazi Germany, in 1933, Dr. Forster met with a group of exiled writers living in Paris and secretly gave them the information about the case. The writer Ernst Weiss, that was also a physician, latter used this information in order to produce his roman "The Eye Witness", which would be published only in 1963. In 1933, Prof. Forster committed suicide in strange circunstances after successive defamatory statements against him. Also Weiss committed suicide in 1940, when German troops invaded Paris. The Gestapo also murdered several other persons involved in the Hitler's medical chart.
\end{abstract}

Key-words: Hitler, hysterical blindness, history of psychiatry, literature, war neurosis.

Recebido: 23/03/2006 - Aceito: 29/03/2006

1 Professor convidado da Clínica Psiquiátrica da Universidade Ludwigs-Maximillian de Munique, Alemanha.

* Traduzido do alemão por Gabriele Gattaz.

Endereço para correspondência: innerfern@email.de 


\section{Introdução}

“(...) às vezes eu tinha a impressão de que os doentes mentais e os quase loucos tinham mais influência sobre as pessoas saudáveis do que vice-versa."

\section{Ernst Weiss - A Testemunha Ocular}

Esta é a história de um prontuário médico e das pessoas relacionadas a ele: médicos, escritores e militares de alta patente. Do ponto de vista psiquiátrico, pelos critérios atuais, o diagnóstico registrado neste prontuário é de uma anestesia e perda sensorial dissociativas (CID-10: F44.6).

Os episódios que compõem esta história ocorrem em diferentes localidades geográficas. Aparentemente, no início, não há correlação entres os diferentes acontecimentos que serão relatados. Os fatos encontram-se somente pela associação da psiquiatria, da literatura e da história, todos documentados em um romance fictício que une, num casamento curioso, a psiquiatria à política (Bloecker, 1966).

Uma parte da história começa em Munique, uma outra nos leva aos campos de batalha da Primeira Guerra Mundial, na região de Ypern, Bélgica, e a terceira parte acontece em Maehren, na então Tchecoslováquia. Além disso, fatos importantes também se dão em Viena, Praga, Berlim e no região do Báltico. Ao final, todos os fatos nos levam a Paris.

A história deste prontuário médico especial é uma "história triste sem consolação" - usando as palavras de Thomas Mann -, que termina com três assassinatos e dois suicídios. Mas este prontuário desapareceu. Da história, somente resta a parte que virou literatura e pôde ser conservada. $\mathrm{O}$ manuscrito do romance foi achado por acaso.

\section{Robert E. Forster}

Robert Edmund Forster nasceu em 3 de setembro de 1878, filho de Josef Forster, professor de fisiologia e nutrição da Ludwigs-Maximilians-Universitaet de $\mathrm{Mu}$ nique, Alemanha, e de sua esposa Wilhelmina.

A família do pai é procedente da região do lago de Constança, na bacia do rio Reno. Sua mãe, oriunda de uma família patrícia conhecida de Augsburgo, na Baviera, era parente do major Roland von Hoesslin, assassinado em outono de 1944 por causa de sua participação na oposição contra Hitler (nota da tradutora: Roland von Hoesslin, nascido em 21 de fevereiro de 1915, era Major do Exército Alemão. Ele foi informado, em agosto de 1944, por Claus von Stauffenberg, do planejamento de um golpe de estado para depor Hitler. Embora o golpe nunca tenha sido levado a efeito, simplesmente por causa deste conhecimento von Hoesslin foi detido pela Gestapo e morto em outubro de 1944).

Robert Edmund Forster estudou medicina em várias faculdades européias. Concluiu o seu doutorado em 1901, em Estrasburgo, com um trabalho sobre neurofisiologia. Em 1909, recebeu sua livre-docência na universidade Charité, em Berlim.

A vocação de Forster para a psiquiatria surgiu após alguns anos de trabalho no departamento de Anatomia, em Genebra e em Halle. Da mesma forma, ele também se interessou pela medicina militar, ingressando no Corpo Médico Militar da Marinha Imperial em agosto de 1898. Dezesseis anos depois, em agosto de 1914, tornouse médico-chefe da Marinha. Tendo atuado inicialmente no hospital militar Kiel-Wik e na Escola de Oficiais da Marinha, Forster foi convocado, em 1916, após a invasão da Bélgica, para assumir a posição de capitão-tenente no Hospital de Guerra da Marinha em Bruges. Seu superior era o Dr. Heinrich Schmidt, médico-chefe-general e diretor do Hospital de Guerra da Marinha, que escreveu, em 1918, o seguinte sobre Forster:

"O médico da Marinha, professor doutor Forster trabalhou do dia $1^{\circ}$ de janeiro de 1915 ao dia 3 de setembro de 1918 como médico-chefe no departamento de Psiquiatria do Hospital de Guerra II da Marinha. Em tempos de paz, ele era livre-docente no departamento de psiquiatria da Faculdade de Medicina da Universidade Charité de Berlim. Graças aos seus amplos conhecimentos científicos, ele tinha grande sucesso no departamento. Era um excelente clínico e também um experiente perito para a Corte Militar. Como era uma pessoa muito enérgica e viva, ele empenhava-se particularmente no tratamento de pacientes acometidos pelas chamadas neuroses de guerra. Em alguns casos, porém, atuava de forma bruta, exigindo do paciente a mesma força de vontade que ele tinha para trabalhar. Seus colegas gostavam dele por seu jeito gentil e incentivador. Nos últimos meses, dava também aulas de histologia na Universidade de Gent. Durante a guerra, ele foi condecorado com a Cruz de Mérito de Primeira e Segunda Classes" (Horstmann, 2004).

Nesse contexto, torna-se importante ressaltar os trabalhos científicos realizados por Forster, como A guerra e as neuroses traumáticas (Der Krieg und die traumatischen Neurosen), em 1915, e O tratamento da fobia de guerra (Zur Behandlung der Kriegszitterer), em 1917. O trabalho mais importante de Forster é, provavelmente, Reação histérica e simulação (Hysterische Reaktion und Simulation), artigo publicado em 1917 no Monatschrift für Psychiatrie und Neurologie, editado por Karl Bonhoffer.

A suposta "brutalidade" de Forster no manejo de seus pacientes, mencionada pelo Dr. Heinrich Schmidt, foi também assinalada por um de seus assistentes, que revelou que "o médico achava que, na maioria dos casos de comportamento histérico, o paciente estava fingindo", o que o levava muitas vezes a gritar com seus pacientes. Forster definia a histeria como uma simulação carregada de emoções: os sintomas histéricos seriam 
comportamentos motivados pela intenção de obter alguma vantagem (Binion, 1978).

Em um artigo sobre $O$ sistema nervoso, publicado em 1922 no Tratado de Fisiologia Patológica, Forster escreve com evidente desprezo sobre os neuróticos de guerra:

“... que, de medo do front, produzem todos os tipos de sintomas histéricos, e com isso conseguem ser mandados para hospitais ou mesmo para casa, se avaliados por médicos pouco especializados. Esses indivíduos sabem muito bem usar essas técnicas histéricas para serem atendidos em suas solicitações antes mesmo que pacientes mais graves.”

Este comportamento impulsivo de Forster, além de sua concepção sobre a histeria, foram mais tarde criticados pela comunidade acadêmica e prejudicaram sua ascensão na carreira universitária (Binion, 1978).

No dia 15 de novembro de 1918, Forster deixou o Corpo Militar. Ele foi condecorado tanto com a Cruz de Mérito de Primeira e Segunda Classes como com a Cruz Hanseática de Hamburgo e a Cruz de Mérito Militar da Bavária de Quarta Classe.

\section{Internação psiquiátrica}

A segunda parte desta história ocorre na região de Ypern, uma região montanhosa da Bélgica. Em outubro de 1918, durante um ataque inglês ao sul de Werwik, o cabo Adolf Hitler, mensageiro do 16을 Regimento Bávaro de Infantaria, ficou temporariamente cego em conseqüência de um ferimento provocado por uma granada de gás mostarda (versão oficial).

Na Primeira Guerra Mundial, foram registrados vários casos da chamada cegueira histérica, de origem psicossomática. Essa cegueira era considerada uma variação das diversas histerias de guerra, que se manifestavam devido à sobrecarga emocional no front, principalmente nas situações de combate homem-a-homem. Obviamente, a cegueira resultante de uma lesão física real, provocada, por exemplo, por uma granada de gás, era muito mais comum (Trapp, 1968).

Depois de alguns dias de internação em Oudenaarde e Gent, o paciente Adolf Hitler foi transferido para a enfermaria psiquiátrica IV do Hospital de Reserva da Prússia Pasewalk, perto de Stettin. Hitler, que ainda se encontrava "cego" no dia 10 de novembro, sabia que a guerra estava perdida para a Alemanha. Porém, apenas três dias depois, foi declarado totalmente apto para o combate, sendo enviado para a tropa de reserva em Munique.

Depois do final da guerra, Hitler decidiu entrar para a política. Nunca mais se falou do médico que o tratou, nem do método de tratamento. Nunca se escutou uma palavra sequer sobre os acontecimentos em Pasewalk. Hitler nunca mais se queixou de distúrbios visuais e não retornou a nenhum médico para dar continuidade ao tratamento. No dia 31 de março de 1920 , em seu relatório de guerra, o próprio Hitler atesta que ele não reivindica nenhuma indenização por ferimentos de guerra.

\section{Ernst Weiss}

A terceira parte da história se passa na região de Maehren. Ernst Weiss, nascido no dia 28 de agosto de 1882 na cidade de Bruenn, era o segundo filho de Gustav Weiss, um comerciante judeu, e de sua mulher Berta. Ernst Weiss perdeu o pai aos quatro anos de idade; posteriormente, esta morte prematura do pai é considerada pela ciência literária como o motivo da criação de personagens paternas dominantes em sua obra.

Depois de se formar no Colégio de Bruenn em 1902, Ernst Weiss estudou medicina em Praga e em Viena, tendo freqüentado as aulas de Freud. Weiss concluiu seu doutorado em 1908 e trabalhou como médico em Berna e em Berlim, respectivamente, com o professor Theodor Kochers e com August Bier. Em 1911, retornou a Viena e passou a trabalhar como cirurgião no hospital de Wieden, dirigido pelo professor Julius Schnitzler, irmão do médico e escritor Arthur Schnitzler.

Dois anos mais tarde, Ernst Weiss iniciou atividade como médico no Navio Áustria, também para tratar de tuberculose. A viagem levou Weiss ao Japão, à China e à Índia. Seu primeiro romance, $A$ Galera (Die Galeere), foi publicado em 1913 pela editora S. Fischer em Berlim.

Weiss veio a conhecer Franz Kafka, que, depois romper seu noivado com Felice Bauer, o acompanhou em viagem de veraneio para a cidade dinamarquesa de Marielyst. Os dois autores tinham praticamente a mesma idade, além de pertencerem à mesma classe social e cultivarem um estilo muito parecido em suas obras literárias.

Em agosto de 1914, Weiss foi convocado para o Regimento de Infantaria de Linz, servindo até o final da guerra como médico de Regimento no front oriental e em diversos hospitais de guerra. Em 1916, Weiss publicou o romance A Luta (Der Kampf) pela editora S. Fischer. Em 1918, foi condecorado com a Cruz de Mérito de Ouro. Weiss trabalhou nessa época como cirurgião em um hospital em Praga e mudou-se, em 1921, para Berlim. Nos anos seguintes, produziu trabalhos literários bastante reconhecidos, como, por exemplo, em 1931, o romance Georg Letham, Médico e Assassino (Georg Letham, Arzt und Mörder). Letham é um anagrama de Hamlet e trata-se de sua última obra antes da emigração para a França.

Depois do incêndio do Parlamento Alemão (Reichstag), em 1933, Weiss viajou a Praga para cuidar de sua mãe, até o falecimento desta em 1934. No mesmo ano, Ernst Weiss emigrou para Paris. Porém, dois anos depois, a atriz Rahel Sanzara, com quem Weiss vinha tendo um longo e próximo relacionamento, veio a falecer 
em Berlim. Como ele mesmo revelava, Weiss sofreu de graves depressões durante esta fase de sua vida.

Do ponto de vista literário, Weiss pode ser comparado a Stefan Zweig e Thomas Mann, tendo dedicado a esses autores, respectivamente, os seus romances $O$ pobre pródigo (Der arme Verschwender), em 1936, e $O$ sedutor (Der Verfuehrer), de 1938.

\section{Paris}

No verão de 1933, depois de Hitler assumir o poder, o professor Edmund Forster viajou a Paris, onde seu irmão Dirk trabalhava como conselheiro da embaixada alemã. Walter Mehring relatou na sua Biblioteca Perdida “o episódio no Café Royale, em Paris, em que aquele psiquiatra [Forster] contou a mim e aos colaboradores do Novo Diário, Leopold Schwarzschild, Josef Roth e Ernst Weiss, sobre o fatal prontuário médico do hospital de guerra de Pasewalk. Isso significava alta traição.” Segundo Mehring, Forster passou três dias com este grupo e entregou a Schwarzschild duas cópias do prontuário de Pasewalk para que ele as guardasse em segurança (Binion, 1978).

Na primeira edição do Novo Diário do dia 16 de setembro de 1933, Leopold Schwarzschild mencionou outro detalhe sobre a estadia de Forster em Paris: "Conversando com um repórter do Novo Diário, Forster haveria dito, com resignação, que finalmente havia chegado a sua hora. Disse também aos repórteres do Novo Diário que não deveriam acreditar em suicídio se ouvissem falar de sua morte nas próximas semanas" (Lewis, 2003).

Schwarzschild escreveu também que Forster tinha contado como ele, enquanto morava em Berlim, havia tratado a cocainomania de Hermann Goering, e que também tinha diagnosticado como psicopata inimputável o ministro da educação nazista Bernhard Rust, acusado de estupro (Binion, 1978).

Segundo Bernhard Horstmann:

"Hoje, depois de pesquisas exaustivas, nós sabemos, com certeza, que aqueles documentos particulares de Edmund Forster, que a Gestapo procurava tão rigorosamente, foram tirados da Alemanha e levados a um grupo de escritores exilados em Paris. Tanto Alfred Doeblin como Ernst Weiss tinham conhecimento médico e cientifico suficientes para entender as anotações clínicas [sobre o caso Hitler] e usá-las em sua obra. Talvez Doeblin, como neurologista e psiquiatra, entendesse ainda mais do assunto. Todavia, Forster decidiu deixar suas anotações com Ernst Weiss, provavelmente porque ele tratava em sua obra literária de temas relacionados à medicina e às ciências naturais. De qualquer forma, foi Weiss quem finalmente usou o conteúdo dos prontuários de Pasewalk em um romance" (Horstmann, 2004).
O historiador americano Rudolf Binion, que teve a oportunidade de falar com um filho de Forster, alertou sobre mais um detalhe:

"Parece que havia também um segundo boletim médico oficial, redigido por Forster e guardado a sete chaves até o começo dos anos 1940 por Wilhelm Canaris, chefe da Defesa do exército alemão, e por Heinrich Himmler" (Binion, 1978).

\section{O suicídio de Edmund Forster e outras perseguições}

Em abril de 1925, Edmund Forster tornou-se catedrático em Greifswald. Ele trabalhava fundamentalmente na área da neurocirurgia, mas também desenvolvia diversos experimentos. Forster chegou a testar em si mesmo os efeitos da substância mescalina, para provar que as alucinações seriam resultado da falha na capacidade de distinguir a imaginação da percepção (Binion, 1978).

No dia 5 de julho de 1933, Forster dirigiu-se de automóvel a Paris, acompanhado de seu assistente-chefe, o doutor Julius Zádor. Apesar de sua elevada qualificação científica, Zádor, que era judeu húngaro, fora reprovado em seu concurso de livre-docência em 1930.

Em 1ํ de setembro de 1933, enquanto Forster comemorava o aniversário de oitenta anos de sua mãe em Nonnenhorn, uma cidade situada na região do Lago de Constança, chegava à sua universidade uma carta do Ministério da Cultura, suspendendo-o imediatamente de seu cargo. No dia seguinte, uma segunda carta assinada pelo mesmo ministério determinava que a diretoria da faculdade efetivasse rapidamente a suspensão do médico, ordenando ainda que fossem especialmente investigadas as acusações contra a ideologia política de Forster (Horstmann, 2004). Essa carta veio acompanhada de uma denúncia de cinco páginas, sendo o autor das denúncias o filho do reitor da faculdade, o estudante de direito Eugen Oklitz, de Berlim. A irmã dele, Luise Oklitz, trabalhava então como assistente de laboratório na clínica psiquiátrica. $\mathrm{O}$ relatório começava da seguinte forma:

"O diretor da clínica psiquiátrica de Greifswald, professor Forster, pensa e raciocina como um judeu. Todos sabem de sua ideologia claramente anti-nacional-socialista, de suas tentativas de ridicularizar o governo e de sua convicção de um 'Quarto Reich'. Todos se revoltam com o fato de que este homem de ideologias marxistas, que foi nomeado catedrático da clínica psiquiátrica de Greifswald por motivos mais que duvidosos, ainda esteja no cargo. Mesmo os seus amigos se perguntam por que este parasita judeu amoral continua dirigindo a sua clínica infestada por idéias amorais, onde os médicos invadem de noite os quartos das enfermeiras...”

O denunciante falava de fotografias pornográficas, difamando as colegas da clínica, que seriam vítimas das orgias alcoólicas de Forster. Finalmente, dizia ele que 
Forster tornara-se catedrático unicamente pelo fato de ter-se casado com a ex-secretária de Matthias Erzberger, político do centro (N.T.: Erzberger assinara o cessarfogo de Compiègne no dia 11 de novembro de 1918 e foi assassinado em 1921 por dois ex-oficiais).

Oklitz atuava por ordem da Gestapo. A carta de denúncias, datada de 16 de agosto de 1933, incluía declarações ofensivas contra personalidades de liderança do Terceiro Reich, insinuações sobre a questão da causa do incêndio do Reichstag, além de relatos de comportamento amoral e desperdício de dinheiro da universidade (a viagem de carro a Paris).

Nesse contexto, Edmund Forster cometeu duas tentativas de suicídio, uma pela ingestão de extrato de nicotina e outra por tentativa de enforcamento. Em ambas as ocasiões, ele foi salvo por sua esposa e por seu colega, o doutor Kroll. Para a família, Forster dizia que o caso não se resolveria com sua demissão, e que ele temia ser levado preso pela Gestapo. Quando aumentou a pressão contra ele, com o reinício dos interrogatórios, ele finalmente se suicidou com um tiro de revólver, no dia 11 de setembro de 1933, em seu apartamento em Greifswald. Ninguém sabia da existência desse revólver. Este é, para Horstmann, um importante indício de que "Forster não somente foi obrigado pelos membros da Gestapo a se suicidar, mas que a Gestapo também providenciou a arma necessária para a execução" (Horstmann, 2004).

É curioso que Forster publicara, no mesmo ano de 1933, um artigo no Jornal Semanal de Medicina de Munique com o título Quando o clínico geral deve suspeitar de idéias suicidas e como ele deve reagir neste caso (Wann muss der praktische Arzt Suizidneigung vermuten und wie verhaelt er sich dann, Münchmner Medizinischen Wochenschrifft, 80p, 1933).

Forster deixou uma esposa e dois filhos, Balduin Konrad e Ruprecht Waldemar, de 13 e 12 anos de idade. Os dois filhos também se tornam médicos. Ruprecht Forster faleceu aos 34 anos, no dia 12 de agosto de 1955, em Basiléia. Balduin tornou-se professor do Instituto de Medicina Forense da Universidade de Friburgo.

O chefe de Forster, professor Karl Bonhoeffer, escreveu no seu necrológio, publicado no Jornal Alemão Semanal de Medicina:

"Professor Edmund Forster, diretor da Clínica Psiquiátrica de Greifswald, em uma forte crise depressiva, terminou espontaneamente com sua vida no dia 11 de setembro. Forster não era um homem comum. Ele podia ser considerado um artista que sofreu bastante por causa do seu temperamento difícil. Todos que trabalharam por mais tempo com ele sabem que sua vida tempestuosa era movimentada por um verdadeiro fanatismo na procura da verdade científica. Dentro dele escondia-se um homem bondoso e fiel, e um médico zeloso. Com sua morte, a Ciência perdeu um excelente neurologista e um clínico estimulador e inovador. A sua luta pela realização da biópsia do cérebro, o seu trabalho científico que provou a existência de espiroquetas vivas no cérebro do sifilítico com paralisia geral progressiva, o seu tratamento da sífilis e os seus estudos no líquor de pacientes com tumor cerebral, demonstram suas excelentes contribuições científicas. Os seus trabalhos sobre a afetividade e a histeria, sobretudo, caracterizam bem o cientista Forster".

Edmund Forster não foi a única vítima do prontuário médico de Hitler: o médico doutor Karl Kroner, nascido em 1878, também atuou no caso do cabo Hitler, confirmando o diagnóstico de cegueira histérica feito por Forster. Em março de 1943, Kroner relatou este fato ao Escritório Americano de Serviços Estratégicos (US Office of Strategic Service - OSS). Em 1938, no dia seguinte à Noite dos Cristais (N.T.: Reichspogromnacht ou Reichskristallnacht: Noite de Cristais - noite de 9 a 10 de novembro de 1938, quando todas as sinagogas da Alemanha foram incendiadas. Esta data marca o começo da destruição em massa do povo judeu pela Alemanha Nazista), Kroner foi detido e enviado para o campo de concentração de Oranienburg, de onde foi solto 13 dias depois graças à intervenção do embaixador da Islândia, conhecido de sua esposa. Com a condição de deixar o país em 24 horas, Kroner fugiu inicialmente para Copenhague e depois para Islândia, onde viveu com sua família até 1945. Após o término da guerra, mudou-se para os Estados Unidos, onde morreu em 1954.

O coronel Ferdinand Eduard von Bredow, que mandou guardar os documentos do hospital militar de Pasewalk, reconheceu o conteúdo comprometedor do boletim e comentou com outras pessoas que a cegueira de Hitler de outono de 1918 era unicamente de origem histérica. Foi detido pela Gestapo e assassinado na madrugada do dia 1을 je julho de 1934 (a Gestapo afirmou que ele estava fugindo).

Pouco tempo antes, o General Kurt Schleicher, que também tinha conhecimento do dossiê, foi assassinado juntamente com sua esposa.

O caso do professor de psiquiatria da Universidade de Heidelberg, Karl Wilmanns, mostra também como a Gestapo observava todos os envolvidos no caso da neurose de guerra de Hitler. Segundo boatos, Hitler foi examinado e tratado numa clinica psiquiátrica em Heidelberg. Esse fato não é verídico, mas o professor Wilmanns, em suas aulas, chamava Hitler de "histérico" em frente aos seus alunos. Logo após Hitler assumir o poder, Wilmanns foi detido e interrogado pela Gestapo, perdendo em seguida todos os cargos (Waite, 1977). Esse episódio mostra que a perseguição rigorosa de todas as pessoas possivelmente envolvidas com um histórico psiquiátrico do novo Chanceler do Terceiro Reich (Reichskanzler) era uma campanha meticulosa e bem dirigida (Horstmann, 2004).

\section{Ernst Weiss e a testemunha ocular}

Em Paris, o médico e escritor Ernst Weiss escreveu a sua última obra literária, o romance $A$ Testemunha Ocular 
(Der Augenzeuge). Trata-se de um romance político, cujo personagem central é um médico (isso é comum na obra de Weiss). As seguintes frases ilustram a preferência deste personagem pela área da psiquiatria:

"Eu me interessei por um fenômeno que, na época, era estudado mais profundamente pela jovem escola dos psiquiatras judeus e sob a influência de Charcot: a histeria e os chamados distúrbios psicógenos, provocados pela mente. Trata-se, em parte, de distúrbios mecânicos, como, por exemplo, as dificuldades para andar, mas também de distúrbios funcionais, como a cegueira, a surdez, a mudez e a anestesia histéricas. Trata-se da procura do caminho que leva da mente consciente [N.T.: o autor chama de Tagesseele] para a mente profunda [N.T.: o autor chama de Unterseele], em que a hipnose e a análise são de grande valia. Esta área de estudo também é interessante para fins legais, pois os distúrbios psicógenos são freqüentemente relacionados à simulação, e eu me tornei especialista no assunto...” (Weiss, 1966: 287p).

Justamente esta última frase parece se referir ao trabalho científico de Forster e às suas publicações sobre reação histérica e simulação. Mas essa sugestão está errada. O personagem principal do romance não é Edmund Forster, pois somente os fatos que se passam no hospital de guerra de Pasewalk coincidem com a biografia dele.

Numa autobiografia fictícia, o psiquiatra sem nome do romance de Weiss, nascido no sul da Alemanha, conta sua vida do final do século XIX até os tempos da Guerra Civil Espanhola. Já as primeiras frases deixam bem claro qual seria o episódio central do romance:

"Eu fui destinado a desempenhar um papel significativo na vida de um homem estranho, o qual, depois da I Grande Guerra, viria a provocar imenso sofrimento e mudanças radicais na Europa. Muitas vezes pergunteime o que me teria levado, naquela época, no outono de 1918, a intervir daquela forma: se era curiosidade - a qualidade principal de um cientista trabalhando na área médica - ou o desejo de ser como um deus e mudar o destino de uma pessoa" (Weiss, 1966: 7p).

O médico, portanto, encontra esse "homem estranho" no hospital de guerra de Pasewalk. Ele é "uma pessoa agitada, que sofre de insônia e de cegueira em consequiência da guerra; um cabo do Regimento Bávaro de List, ordenança do Estado Maior do Regimento, A.H. Ele é condecorado - como o médico também - com a Cruz de Mérito de I⿳亠口冋 Classe.

"Alertaram-me de que ele era uma pessoa fanática e querelante que sempre perturbava, agitava e comandava, e contra o qual seria necessário tomarmos medidas disciplinares severas" (Weiss, 1966: 133p).
O historiador Rudolf Binion afirmou, convencido: "Com certeza o personagem A.H. do romance de Weiss é o 'neurótico de guerra' que Forster descreve" (Binion, 1978).

\section{O médico do romance também sabia que:}

"O destino de uma pessoa que sofre de cegueira histérica é fatal. Esta pessoa é mais aleijada do que alguém que tem duas próteses no lugar das pernas. Ela é mais infeliz do que um 'cego de verdade'... Os cegos de verdade conseguem enxergar com a alma; os cegos histéricos, não... Seria possível curar este paciente? Eu pensei muito e cheguei finalmente a uma conclusão: eu poderia tentar libertá-lo de seus sintomas fazendo-o acreditar em uma engenhosa analogia de seu sofrimento com a sua ânsia por prestígio e o desejo de tornar-se semelhante a Deus, e com sua energia descomunal. Isto poderia liberá-lo dos sintomas. Eu não aceitava a idéia de não poder curá-lo. Neste ponto eu estava cego. Não queria enxergar porque eu havia me apaixonado pelo caso. Eu também queria atuar, tinha que agir. Eu queria dominar, e todo ato significa um domínio, uma modificação e intervenção ativa no destino. A.H. também interveio no destino, ele preferiu ficar cego a ter que assistir à queda da Alemanha, o que demonstra uma força de vontade extrema” (Weiss, 1966: 143p).

Este é o eixo do romance: em 1918, no hospital de guerra de Pasewalk, um psiquiatra cura, mediante a hipnose e a auto-sugestão, o paciente A.H. de sua cegueira histérica. $\mathrm{O}$ médico não consegue libertar o paciente de suas ideologias políticas e do seu ódio, mas é bem-sucedido em restabelecer e inflar a sua autoconfiança, o que - do ponto de vista do médico - o faz co-responsável pela terrível carreira e ascensão de A.H.; esta é a interpretação do médico e o motivo para o seu desespero profundo.

Como o médico mantinha consigo esses documentos secretos e, além disso, era casado com uma judia, ele é enviado em 1933 a um campo de concentração, onde quase veio a falecer em consequiência de graves espancamentos sofridos. No entanto, consegue ser libertado porque sua mulher entrega os documentos a um ajudante de Roehms, na Suíça. Física e psiquicamente debilitado, ele se desespera, porque a sua liberdade fora comprada. Ele decide ir para a Espanha e ajudar, como médico, os defensores da República na luta contra $o$ fascismo.

Apesar da estatura franzina, Ernst Weiss era uma pessoa sensível. Esperando receber uma ajuda financeira, pois era um escritor pobre, inscreve o manuscrito deste romance no concurso American Guild for German Cultural Freedom. Lion Feuchtwanger, Thomas Mann, Bruno Frank e Rudolf Gilden faziam parte do júri. Weiss sabia ser um autor alemão de renome, mas, naquela época, já estava recebendo ajuda financeira desta or- 
ganização, além de contribuições financeiras pessoais de Thomas Mann e Stefan Zweig. Em 1939, apesar de ter revisado todo o manuscrito, Weiss não conseguiu o resultado esperado no concurso. Com isso, tornou-se cada vez mais depressivo, se suicidando em 15 de junho de 1940, quando as tropas alemãs invadiram Paris: em seu quarto de hotel, ele entrou na banheira, cortou os pulsos e tomou veneno, falecendo na noite seguinte no Hospital Lariboisière. Seu túmulo, no Cimetière de Pantin, desapareceu há muito tempo.

O suicídio não era um fenômeno raro entre escritores exilados, como, por exemplo, Walter Benjamin, Walter Hasenclever, Ernst Toller e Stefan Zweig. O que é trágico nesta história de Weiss é que pouco tempo depois de cometer suicídio, a tão esperada ajuda seria concretizada: Thomas Mann, usando seu relacionamento com Eleanor Roosevelt, estava prestes a conseguir para Weiss um visto para os Estados Unidos e um emprego como leitor em Hollywood (Horstmann, 2004).

O romance $A$ Testemunha Ocular foi publicado postumamente em 1963 pela pequena editora Kreisselmeier (Icking/Munique). O título, todavia, foi modificado para Eu, a Testemunha Ocular (Ich, der Augenzenge).
Esta modificação era juridicamente necessária porque, em 1959, havia sido publicado pela editora Hanser o romance de Alain Robbe-Grillets Le Voyeur, cujo título em alemão era Der Augenzenge. O título original pôde ser usado somente em 1982, quando a editora Suhrkamp publicou todas as obras de Ernst Weiss em 16 volumes em memória ao seu centenário do nascimento.

Ana Seghers homenageou o médico e escritor Ernst Weiss em seu romance Transit, através do personagem do poeta Wedel. Mesmo assim, Weiss faz parte dos "tragicamente esquecidos" (Bloecker, 1966). Embora Weiss tenha sido declarado por seu amigo e companheiro Hermann Kersten "um dos romancistas europeus mais importantes do século XX", até hoje ele permanece na lembrança dos leitores e dos críticos como um escritor desconhecido e, sobretudo, subestimado.

O boletim médico de Hitler continua desaparecido. Isso não evitou, todavia, que os fatos relacionados à sua internação em Pasewalk e o seu diagnóstico ficassem conhecidos. Os fatos aqui narrados permitem especular sobre as consequiências terríveis que a psicopatologia nele descrita, assim como o seu tratamento, podem ter tido para a humanidade.

\section{Referências bibliográficas}

Arnold, H.L. (Hrsg.): - Ernst Weiß. Text und Kritik. Band 76. Munique, Edition text+kritik, 1982.

Binion, R. - ...dass ihr mich gefunden habt. Hitler und die Deutschen. Eine Psychohistorie. Klett-Cotta, Stuttgart, 1978.

Blöcker, G. - Literatur als Teilhabe. Kritische Orientierungen zur literarischen Gegenwart. Argon, Berlin, 1966.

Forster, E. - Hysterische Reaktion und Simulation. In: Monatsschrift für Psychiatrie und Neurologie, Bd. LXII/1917, pp. 298-324; 370-381.

Horstmann, B. - Hitler in Pasewalk. Die Hypnose und ihre Folgen. Droste, Düsseldorf, 2004.
Lewis, D. - The Man Who Invented Hitler. The Making of the Führer. Headline Publishers, Londres, 2003.

Mehring, W. - Die verlorene Bibliothek. Autobiografie einer Kultur. Kreisselmeier, Icking/Munique, 1964.

Trapp, F. - Der Augenzeuge - ein Psychogramm der deutschen Intellektuellen zwischen 1914 und 1936. Büchergilde Gutenberg, Frankfurt/Main, 1986.

Waite, R.G. - The Psychopathic God: Adolf Hitler. Nova York, 1977.

Weiss, E. - Ich-Der Augenzeuge. Mit einem Nachwort von Hermann Kesten. Büchergilde, Frankfurt/Main, 1966. 